\title{
How Wi-Fi came to El Chaco
}

\author{
Klaus Stoll \\ Fundacion Chasquinet \\ Quito, Ecuador \\ < klaus@,chasquinet.org >
}

What happens in the following story is nothing out of the ordinary; it is just how Wi-Fi came to the community of EL Chaco.

El Chaco is a small town about $21 / 2$ hours by car east of Quito on the edge of the Ecuadorian Amazon rainforest. Its 6,000 inhabitants earn a living mostly from agriculture or small businesses when they have not left to seek their fortune in Quito or in other countries. El Chaco is neither rich nor poor, nobody is starving and nobody has riches, the people of EL Chaco have learned to make do with the basics. The same is true for the town's infrastructure. El Chaco has schools but they are in a bad state, El Chaco has a health station but no hospital and a doctor is often hard to find, El Chaco has access to the phone but the lines are rare and calls expensive, El Chaco has roads, some good, mostly bad, sometimes impassable.

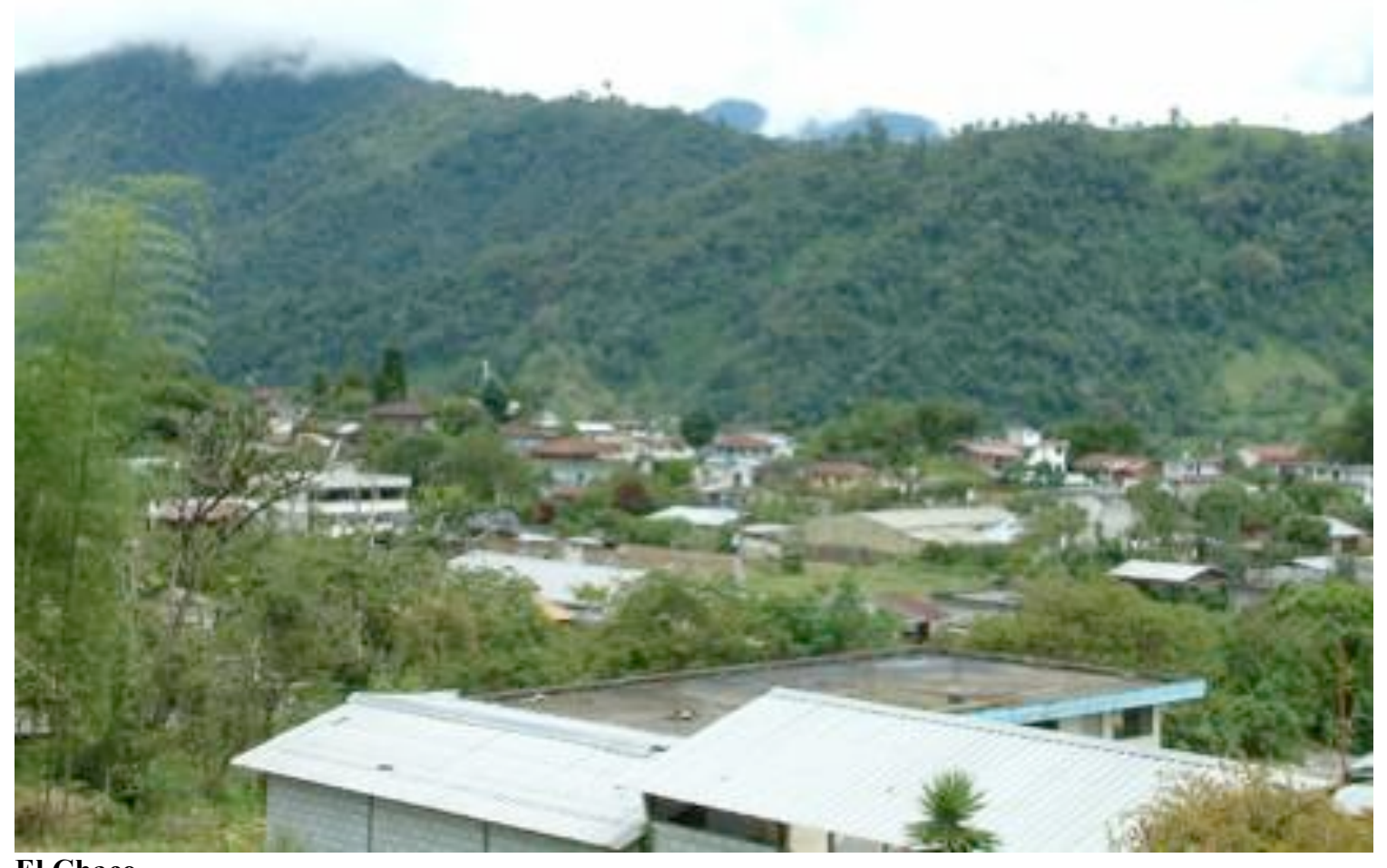

\section{El Chaco}

The only special features that El Chaco has to offer, (besides the outstanding natural beauty that so often can be found in Ecuador), is an oil pipeline that runs straight through it and the river nearby which is a paradise for all kinds of water sports like rafting and kayaking and ranks as one of the best in the world.

Fundacion Chasquinet is a small NGO based in Quito Ecuador. The work Chasquinet does can be simply described as supporting the strategic use of the available information and communication 
technologies in the social sector, working on a national and international basis with telecenters, schools, hospitals and NGO's. Chasquinet has established over the years an "open door" policy, meaning that Chasquinet will not go into communities and establish its own projects but will wait until the communities come to Chasquinet and ask for support. In this way it is ensured that the work Chasquinet is doing is based on the real needs of the communities and not the needs perceived by Chasquinet for a community. Chasquinet enters a partnership with the communities and the goal of these partnerships is community development.

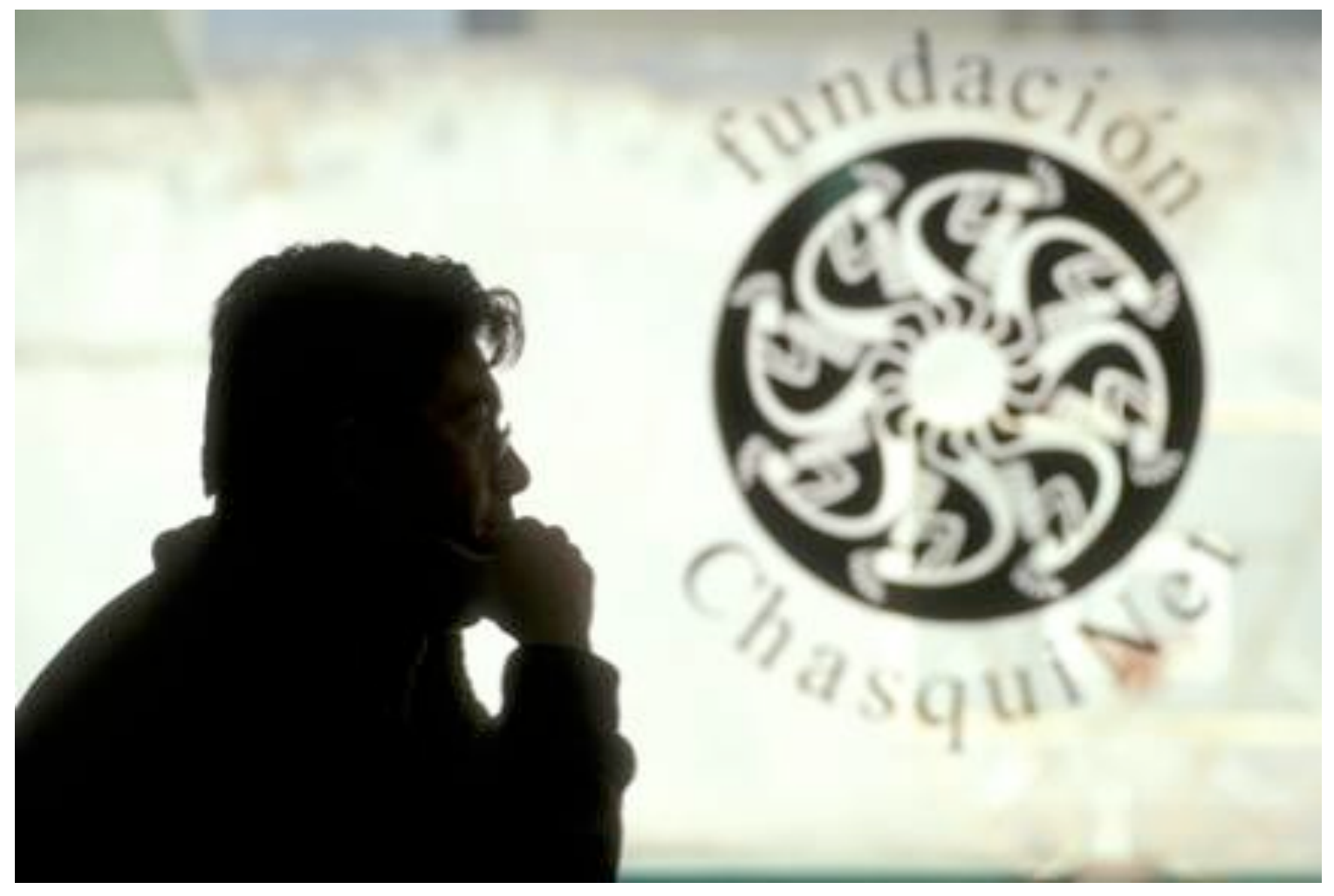

In 2003 the Canadian International Development Research Center (IDRC) and the Institute for Connectivity in the Americas (ICA) contacted Chasquinet to ask if we would be able and willing to pilot Wi-Fi equipment in Ecuador. The equipment was from the Canadian company EION and consisted of three Wi-Fi sets with surround coverage of $5 \mathrm{~km}$ with one set having an additional $25 \mathrm{~km}$ point to point connection.

At the same time the community of El Chaco contacted Chasquinet asking us not only to help with their Internet connectivity problem but also to help to make their Information and Communications Technology (ICT's) work for the social and economic development of the whole community.

El Chaco already had experience with the Internet, consisting of a single computer at a restaurant. The connection was expensive and slow but it already had convinced many in El Chaco of the potential of the new ICT's and the first question the community was looking to answer was: How can we connect EL Chaco to the Internet in a cost efficient way? 


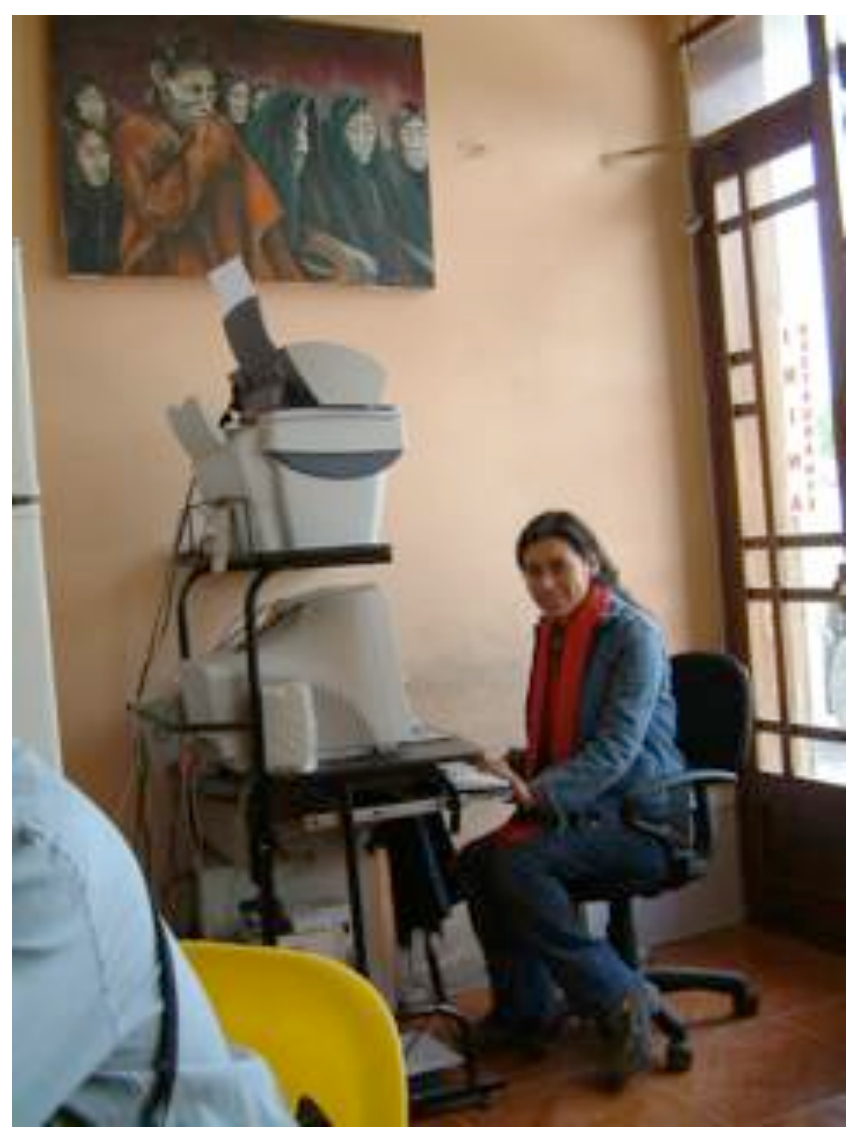

\section{Single Computer Telecenter in EI Chaco}

What better place to test the Wi-Fi Equipment then El Chaco. But installing the equipment is of course, just a small part of a successful project. The most important question that needed answering was:

Connectivity for What?

A series of community meetings was arranged and it soon became clear that what the people of El Chaco wanted to know was: How can the Internet help us in our schools, in our local government, in the small and medium enterprises, in the ecology, the health services and tourism? How can we make it sustainable not only in a financial but also in a technical, social, cultural and political sense?

To find the answers to these questions and to develop a strategic plan for the implementation of the new ICT's, Chasquinet undertook a number of training and planning workshops in El Chaco. However, the training did not just concentrate on the technical aspects of using computers. More important was the training on the strategic use of these technologies: how to use the Internet in schools, how could the local government take advantage, how to document the environmental treasures and how to protect them, how to support the local enterprises, how the local health station could use it, and how could the Internet be used to organize and promote local tourism?

One lesson Chasquinet has learned in the years since it was formed is that social transformation can only come through personal transformation so in addition to the more Internet concentrated workshops a "Healing Touch" workshop was organized for the community. Healing Touch is a medical technique that combines traditional indigenous healing traditions from North and South America; and this proved to be a vital step in the sustainable community development of El Chaco as it responded to deeply rooted medical and cultural needs in the community. 


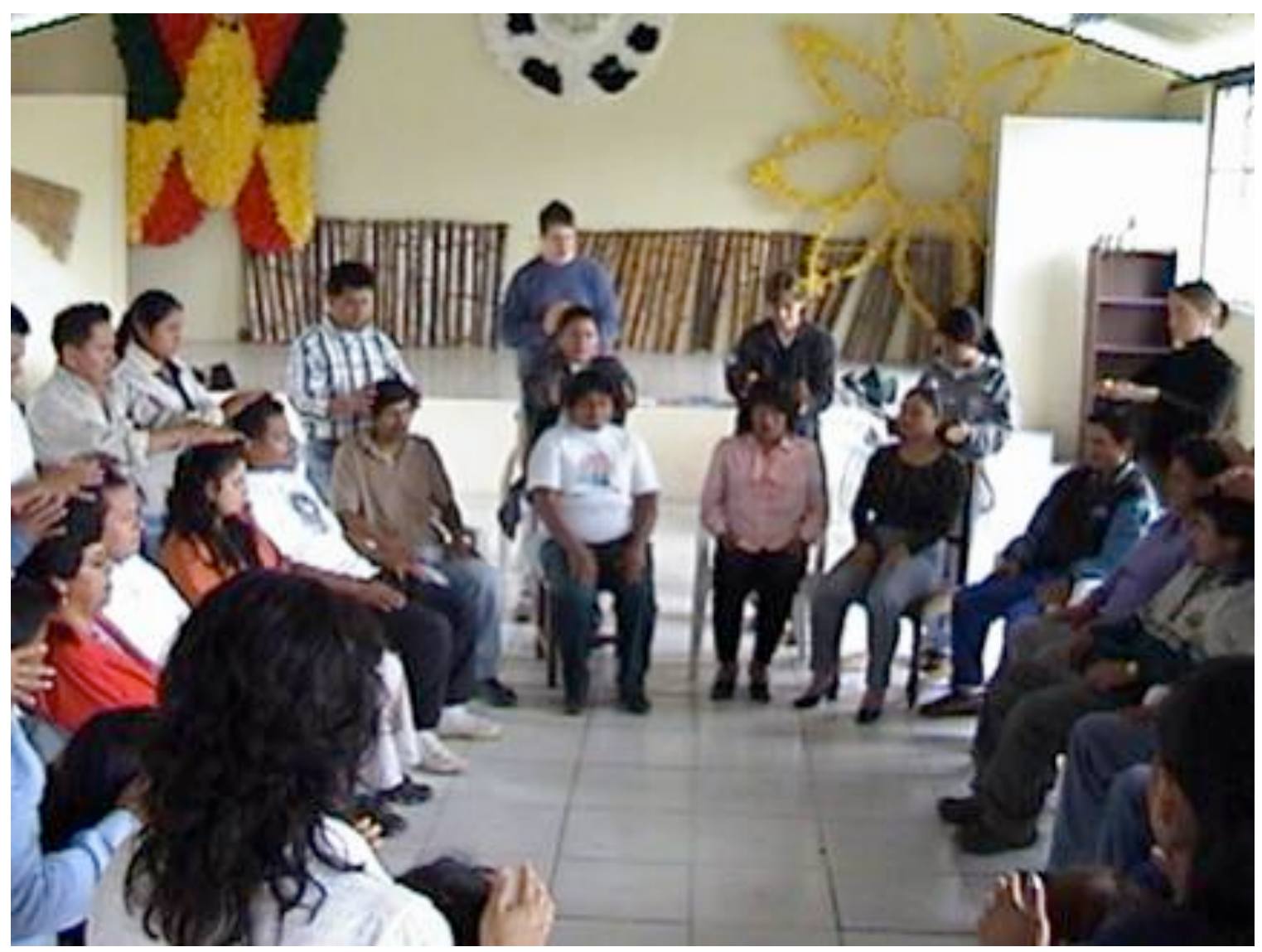

Healing Touch in El Chaco

After six month of training and consultations the community came up with their plan for implementing the Internet in El Chaco. The main points of this plan where:

1. The creation of a Community Telecenter at a community center managed by a local group.

2. In the first phase to only connect the Telecenter, the local Government and the Health Center via $\mathrm{Wi}-\mathrm{Fi}$ to the Internet.

3. The Telecenter would offer not just connectivity services to the community but concentrate on offering training particularly to teachers and pupils, local government officials and local businesses.

4. Additional connections (schools, hotels, businesses, police station and so on) to the Wi-Fi network would be made but only after the respective users had received training at the Telecenter.

The plan was immediately put into action. The Telecenter was created, and the workshops were implemented and soon the Telecenter was a focal point of the community. However, there was still one problem. It was a telecenter without "Tele" ie. without Internet connectivity. Even if Wi-Fi were to be installed at this point, it still needed to be connected to the Internet. Dial-up and any cable based solutions were out of the question due to their very high costs. A technical investigation was undertaken with the conclusion that a combination of VSAT and Wi-Fi would be the best and most cost-effective approach. However, the initial and running costs were still very high. A further solution was found when the local government and the semi-governmental development agency for the Ecuadorian Amazon region, ECORAI, decided to share the connectivity costs. 


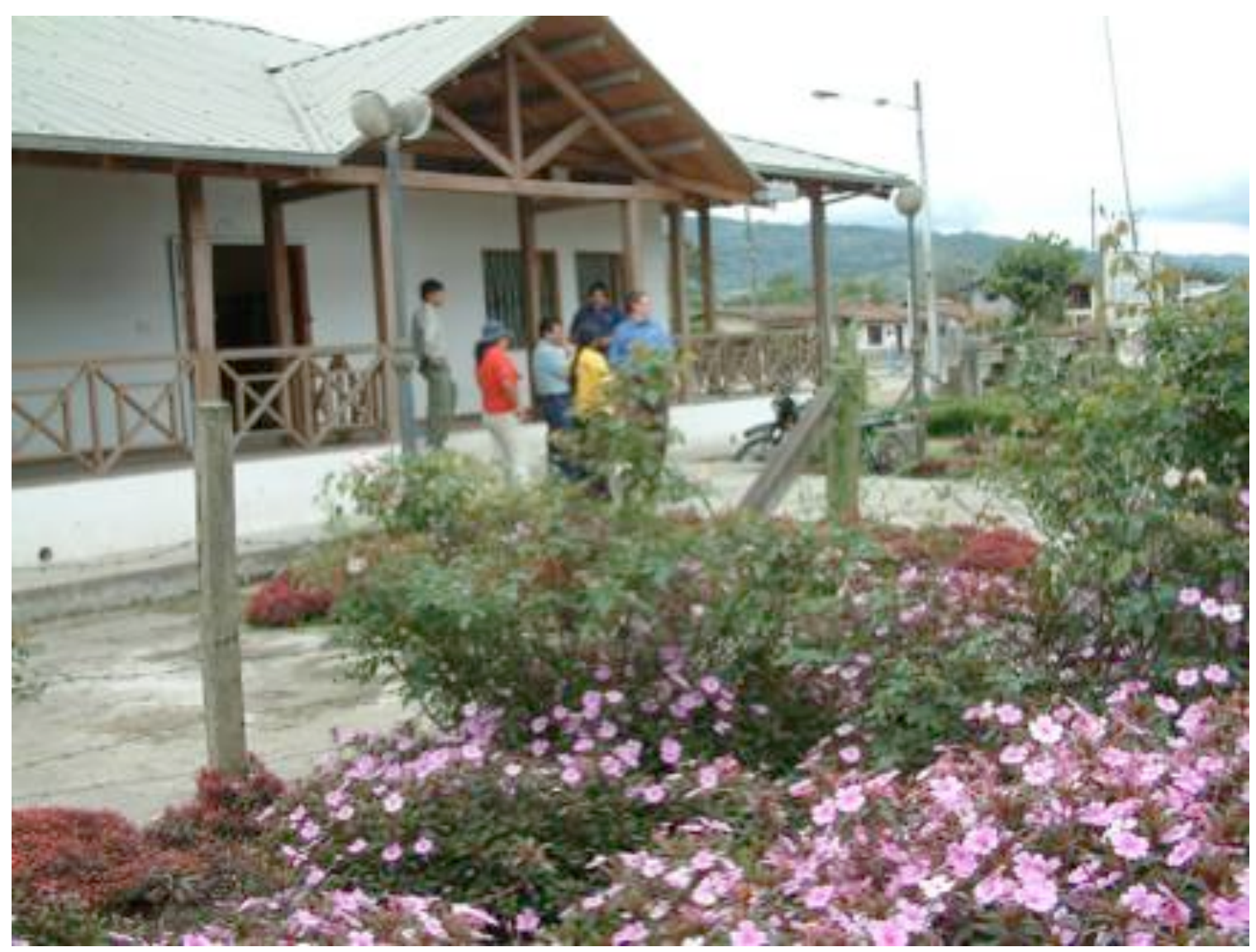

\section{Telecenter El Chaco}

The installation of the EION Wi-Fi equipment turned out easier than we first expected. Everybody involved was nervous as to whether this new technology would do what it promised but after just a day and a half of installation the Wi-Fi worked just fine. Throughout the installation local technicians from the telecenter took part in order to learn how the system worked. In this way they would be would enabled to maintain the system in the future and to act as "experts" for further installations. 


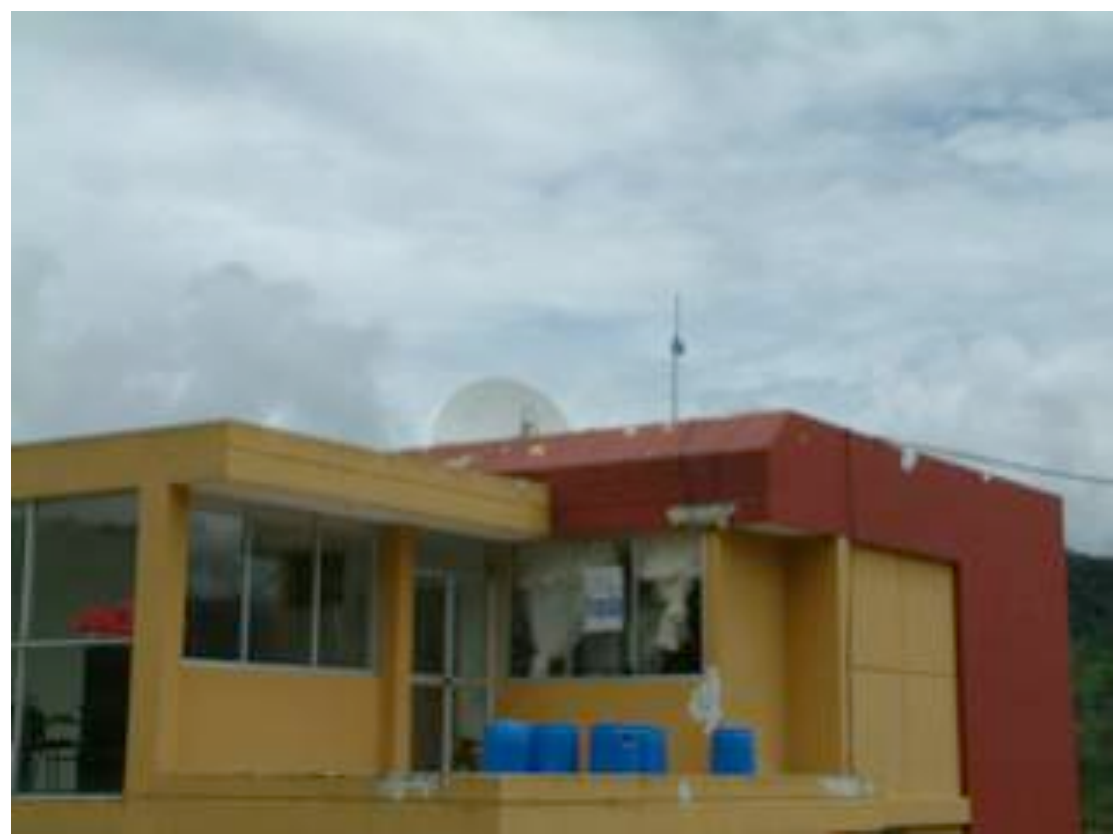

Health Station with VSAT and Wi-Fi Antennas

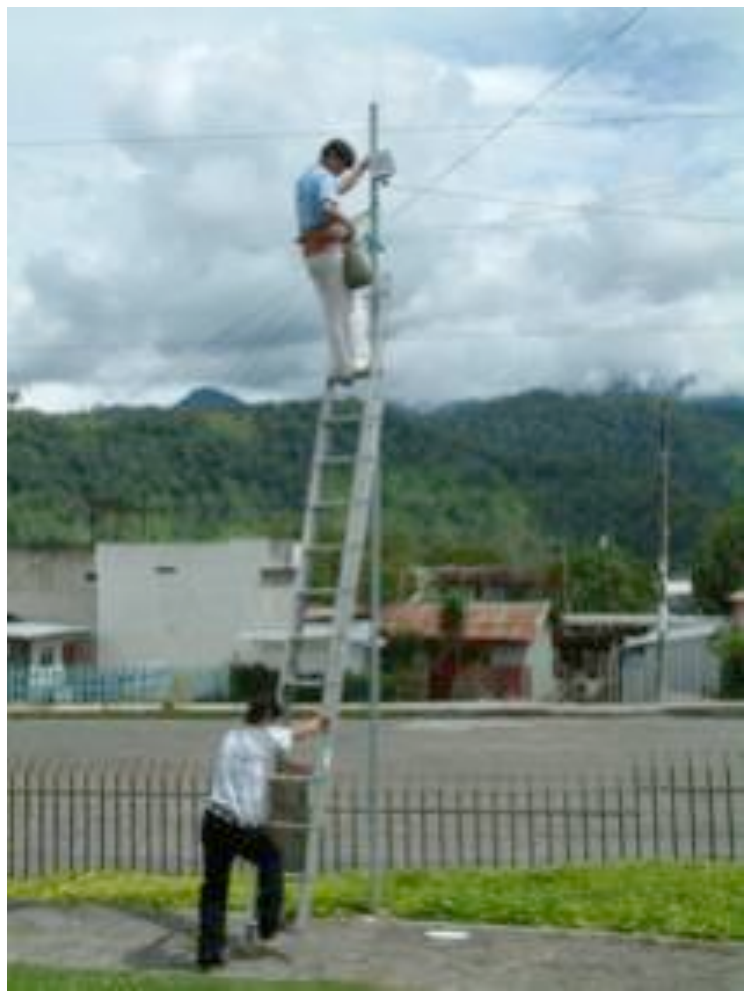

Local technicians during installation.

El Chaco was now on the Net and even with only three initial connection points the impact could be felt immediately.

For the first time teachers and pupils had access to high quality teaching materials; families could communicate at a low cost with their loved ones working abroad; the mayor and his staff could now access relevant governmental resources; the nurse could get advice from doctors in Quito; and traders could offer 
their goods outside the local market—-just a few examples among many. As one local woman expressed it: "I feel like El Chaco is for the first time on the map".

This is a perfect example of a how relatively simple and cheap project like Wi-Fi in El-Chaco can have a very big impact.

The main lessons learned from the project are: Wi-Fi in particular in combination with VSAT technology can be a cost effective way to connect rural communities but this connectivity will only have an impact if the system is implemented by the respective community and used by them according to their needs. Training, strategic use and community involvement are more important then the technology itself.

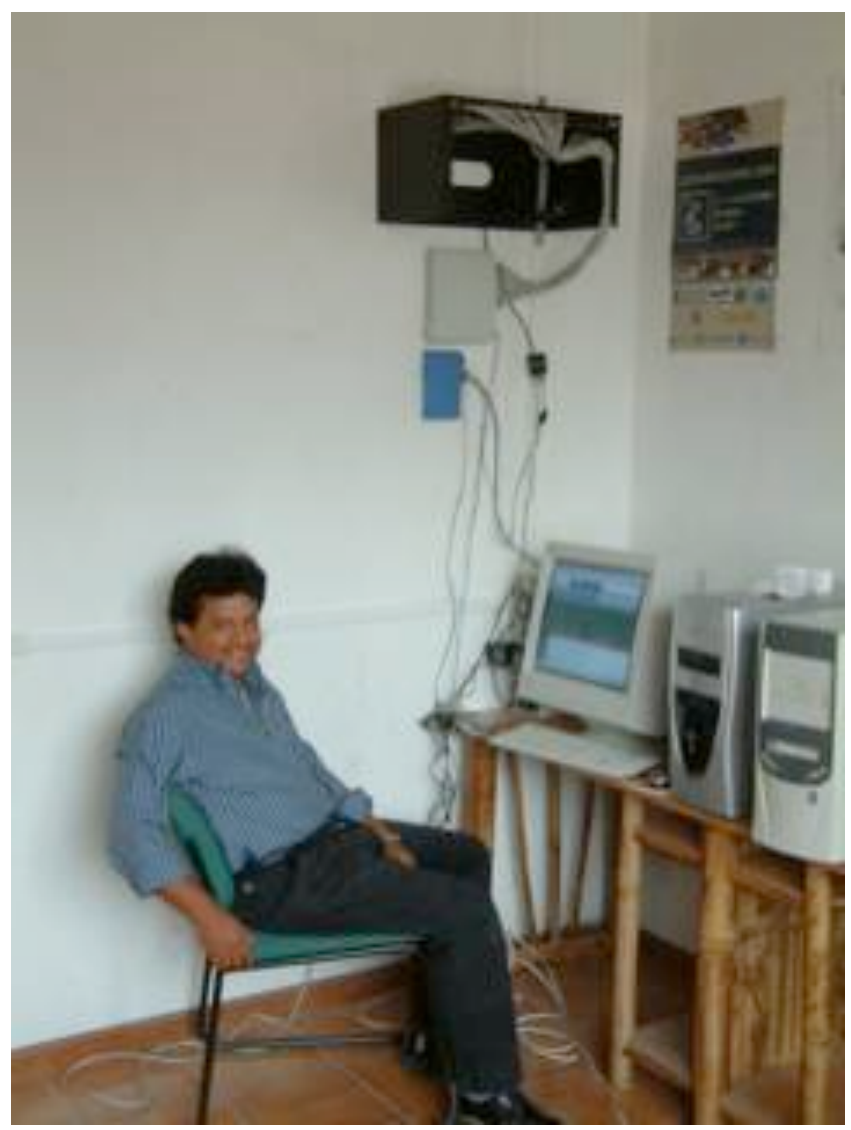

David, a very happy telecenter manager. 